\title{
Microsatellite genotyping of Plasmodium vivax infections and their relapses in pregnant and non-pregnant patients on the Thai-Myanmar border
}

Supinya Thanapongpichat ${ }^{1}$, Rose McGready ${ }^{2,4}$, Christine Luxemburger ${ }^{2,5}$, Nicholas PJ Day ${ }^{3,4}$, Nicholas J White ${ }^{3,4}$, Francois Nosten ${ }^{2}$, Georges Snounou ${ }^{6,7^{*}}$ and Mallika Imwong ${ }^{8^{*}}$

\begin{abstract}
Background: Plasmodium vivax infections in pregnancy are associated with low birth weight and anaemia. This parasites species is also characterised by relapses, erythrocytic infections initiated by the activation of the dormant liver stages, the hypnozoites, to mature. Genotyping of $P$. vivax using microsatellite markers has opened the way to comparative investigations of parasite populations. The aim of the study was to assess whether there were any differences between the parasites found in pregnant and non-pregnant patients, and/or between the admission infections and recurrent episodes during follow-up.

Methods: Blood samples were collected from 18 pregnant and 18 non-pregnant patients, who had at least two recurrent episodes during follow-up, that were recruited in two previous trials on the efficacy of chloroquine treatment of $P$. vivax infections on the Thai-Myanmar border. DNA was purified and the $P$. vivax populations genotyped with respect to eight polymorphic microsatellite markers. Analyses of the genetic diversity, multiplicity of infection (MOI), and a comparison of the genotypes in the samples from each patient were conducted.

Results: The $P$. vivax parasites present in the samples exhibited high genetic diversity (6 to 15 distinct allelic variants found for the 8 loci). Similar expected heterozygosity $\left(H_{e}\right)$ values were obtained for isolates from pregnant (0.837) and non-pregnant patients (0.852). There were modest differences between the MOI values calculated for both admission and recurrence samples from the pregnant patients (2.00 and 2.05, respectively) and the equivalent samples from the non-pregnant patients (1.67 and 1.64, respectively). Furthermore, the mean number of distinct alleles enumerated in the admission samples from the pregnant (6.88) and non-pregnant (7.63) patients were significantly lower than that found in the corresponding recurrent episodes samples (9.25 and 9.63, respectively).

Conclusions: The $P$. vivax populations circulating in inhabitants along the Thai-Myanmar border, an area of low malaria transmission, displayed high genetic diversity. A subtle increase in the multiplicity of $P$. vivax infections in pregnant patients suggests a higher susceptibility to infection. The higher allelic diversity in the relapse as compared to the admission samples in both patient groups is consistent with the hypothesis that a febrile episode promotes the activation of hypnozoites.
\end{abstract}

Keywords: Genetic diversity, Malaria, Plasmodium vivax, Pregnancy, Relapse

\footnotetext{
* Correspondence: georges.snounou@upmc.fr; noi@tropmedres.ac

${ }^{6}$ INSERM UMR-S 945, F-75013, Paris, France

7 Université Paris 6, Pierre \& Marie Curie, Faculté de Médecine Pitié-Salpêtrière,

Paris, France

Full list of author information is available at the end of the article
} 


\section{Background}

Malaria infection during pregnancy substantially increases the risk of morbidity and mortality to the mother, her foetus and the neonate, and thus constitutes an important public health problem [1]. In areas of high endemicity, the nefarious effects of infection by Plasmodium falciparum are most pronounced in primigravidae, and though less severe, infections in subsequent pregnancies remain associated with anaemia and low birth weight [2]. In areas of low endemicity, the relatively low levels of acquired immunity against malaria parasites increase susceptibility to more severe clinical falciparum episodes during pregnancies, which could result in foetal or maternal death [3]. The impact of infection by Plasmodium vivax, the most prevalent parasite in the Asia-Pacific region, is less pronounced than that associated with $P$. falciparum [4]. In a large-scale study conducted on the western border of Thailand, an area of low endemicity, $P$. vivax infections were more common in primigravidae than in multigravidae and were associated with mild maternal anaemia and increased risk of low birth weight [5]. Histopathological examination of the placentas from $P$. vivax-infected and treated women did not reveal any evidence of parasite sequestration or pathological changes [6], thus the pathogenic mechanisms remain unclear.

One salient biological characteristic of $P$. vivax is the formation of dormant liver stages, hypnozoites, by a proportion of the sporozoites inoculated by the infected mosquito. Hypnozoites remain uninucleate and metabolically quiescent for varying durations, that can extend to years, before resuming their development to form mature schizonts that then initiate a new erythrocytic episode upon merozoite release. In tropical areas, $P$. vivax infections have a short latent period (2 to 6 weeks), and the primary episode is often followed by a succession of relapses (every 3 to 4 weeks) that wane in frequency with time [7]. In the mid 1990's, the recurrence rate for $P$. vivax infections treated with chloroquine and followed up for 63 days was found to be $63 \%$ (95\% CI 57-69\%) in non pregnant patients on the ThaiMyanmar border [8]. In a similar study conducted towards the end of the 2000's in adults and children in the same region the recurrence rate following chloroquine treatment increased to $79.1 \%$ (95\% CI, $73.5 \%-84.8 \%$ ), probably because of increased prevalence of chloroquine resistant $P$. vivax [9]. Indeed, the first case of $P$. vivax high-grade resistance to chloroquine in pregnancy was reported recently from the same area [4]. The only drug available to eliminate hypnozoites, thus preventing relapses, is primaquine. Thus, in 1995-1996 when the first $P$. vivax recurrence in non pregnant patients on the Thai-Myanmar border was treated with primaquine and chloroquine the risk of having a further vivax episode within 2 months was reduced by $96 \%$ (95\% CI 83-99\%)
[8]. However, primaquine is contraindicated in pregnancy and in 1986 to 1997 23\% (149/634) of pregnant women had two or more parasitaemia episodes [5].

In recent years, reliable methods to genotype $P$. vivax populations using microsatellites have been developed $[10,11]$. Using this methodology it was revealed that $P$. vivax infections in patients from Thailand, Myanmar and India are often polyclonal, and that the genotype of the parasites in the first relapse following chloroquine treatment [12] differs from that of the initial admission P. vivax population in more than half of the patients. This suggests heterologous activation of hypnozoites, most probably acquired from earlier inoculations. This was supported by data from a study of relapses in infants and in their mothers pre- and post-partum [13] that showed that whereas admission and relapse infections are often genetically heterologous in the mothers, those observed in the children are generally homogeneous. In a recent study $P$. vivax genetic diversity was compared in pregnant and non pregnant patients in Colombia, and found to be similar in both groups [14]. The purpose of the study presented here is to expand knowledge on the genetic diversity of $P$. vivax in pregnancy beyond the few studies quoted above. Given the altered immunological and physiological status in pregnancy, it was considered important to ascertain whether the pattern of relapse and the genetic diversity of the $P$. vivax populations observed differed between pregnant and nonpregnant patients. To this end, a genetic analysis was conducted on archived samples that had been collected in the course of drug treatment studies conducted in villages along the Thai-Myanmar border.

\section{Methods}

\section{Study site and collection of blood samples}

The studies took place in the Shoklo Malaria Research Unit clinics on the Thailand-Myanmar border, an area of low (estimated entomologic inoculation rate of one or less infectious bites per year) and seasonal malaria transmission [15]. The samples were derived from two previous trials on the efficacy of chloroquine in the treatment of $P$. vivax. The group of $P$. vivax-infected non-pregnant women represented all those patients with two relapses recruited between July 1995 and July 1996 [8], and in pregnant women recruited between November 1998 and January 2000 [16]. In both patients groups $P$. vivax was confirmed by blood smear and given a treatment with chloroquine (Government Pharmaceutical Organization, Thailand) using the following schedule: $15 \mathrm{mg}$ base $/ \mathrm{kg}$ on the first day, followed by $5 \mathrm{mg}$ base $/ \mathrm{kg}$ daily on the second and third day (total $25 \mathrm{mg}$ base $/ \mathrm{kg}$ ). The nonpregnant patients were followed up for 63 days and any recurrent parasitaemia was recorded, treated appropriately and the patient followed up for a further 63 days. Pregnant patients were followed up until delivery. At 
Table 1 Characteristics of pregnant and non-pregnant $P$. vivax patients

\begin{tabular}{|c|c|c|c|}
\hline Characteristics & Pregnant patients & Non-pregnant patients & $p$-value \\
\hline & $\mathrm{N}=18$ & $\mathrm{~N}=18$ & \\
\hline Age $\left(\right.$ years) ${ }^{a}$ & $24 \pm 7(15-40)$ & $14 \pm 10(5-46)$ & $<0.001$ \\
\hline Weight $(\mathrm{kg})^{\mathrm{a}}$ & $48 \pm 6(41-62)$ & $29 \pm 12(13-48)$ & $<0.001$ \\
\hline \multicolumn{4}{|l|}{ Previous $P$. vivax malaria } \\
\hline During previous (year) ${ }^{b}$ & $5 / 18(27.8)$ & 15/18 (83.3) & 0.003 \\
\hline$>1$ episode during previous (year) ${ }^{b}$ & $1 / 5(20.0)$ & $8 / 15(53.3)$ & 0.436 \\
\hline Time since the last episode (days) ${ }^{c}$ & $62(21-102)$ & $65(36-218)$ & 0.432 \\
\hline \multicolumn{4}{|l|}{ Previous $P$. falciparum } \\
\hline During previous (year) ${ }^{b}$ & $4 / 18(22.2)$ & $7 / 18(38.9)$ & 0.469 \\
\hline$>1$ episode during previous year ${ }^{\mathrm{b}}$ & $1 / 4(25.0)$ & $1 / 7(14.3)$ & 0.712 \\
\hline Time since the last episode (days) ${ }^{c}$ & $26(21-98)$ & $55(44-362)$ & 0.088 \\
\hline Characteristics of infection at 1 st genotype on day admission & $N=18$ & $N=18$ & \\
\hline Proportion with a history of fever ${ }^{b}$ & $13 / 18(72.2)$ & $18 / 18(100.0)$ & 0.205 \\
\hline Duration of fever (days) ${ }^{c}$ & $3(1-7)$ & $2(1-7)$ & 0.016 \\
\hline Proportion febrile ${ }^{b}$ & $6 / 18(33.3)$ & 10/18 (55.6) & 0.314 \\
\hline Temperature $\left({ }^{\circ} \mathrm{C}\right)^{\mathrm{a}}$ & $37.1 \pm 1.4(35.5-39.7)$ & $37.8 \pm 1.0(36.8-39.9)$ & 0.134 \\
\hline Haematocrit (\%) ${ }^{a}$ & $32 \pm 6(17-42)$ & $37 \pm 3(31-42)$ & 0.002 \\
\hline Parasitaemia (uL) ${ }^{\mathrm{d}}$ & $943(32-11,492)$ & $1,991(43-25,844)$ & 0.248 \\
\hline Time to 1 st reappearance $(\text { days })^{c}$ & $45(25-71)$ & $43(35-52)$ & 0.495 \\
\hline Characteristics of patients on day of follow up & $N=44$ & $N=36$ & \\
\hline Proportion with a history of fever ${ }^{b}$ & 22/44 (50.0) & $32 / 36(88.9)$ & $<0.001$ \\
\hline Duration of fever in days (range) ${ }^{\mathrm{e}}$ & $2(1-3)$ & $1(1-3)$ & 0.013 \\
\hline Proportion febrile & $11 / 44(25.0)$ & 29/36 (80.6) & $<0.001$ \\
\hline Mean temperature $\left({ }^{\circ} \mathrm{C}\right)^{\mathrm{a}}$ & $36.9 \pm 1.1(35.0-39.7)$ & $38.1 \pm 1.0(35.8-40.8)$ & $<0.001$ \\
\hline Haematocrit (\%) ${ }^{a}$ & $31 \pm 3(23-39)$ & $38 \pm 3(30-46)$ & $<0.001$ \\
\hline Parasitaemia (uL) ${ }^{\mathrm{d}}$ & $637(16-3,624)$ & $1,581(36-22,272)$ & 0.022 \\
\hline \multicolumn{4}{|l|}{ Interval times to reappearance (days) } \\
\hline 1 st reappearance to 2 nd reappearance $(\text { range })^{c}$ & $51(28-98)$ & $48(33-64)$ & 0.468 \\
\hline 2 nd reappearance to 3 rd reappearance $(\text { range })^{c}$ & $51(28-66)$ & - & - \\
\hline 3 rd reappearance to 4 th reappearance $(\text { range })^{c}$ & $32(28-35)$ & - & - \\
\hline
\end{tabular}

a mean \pm SD (min-max).

b Number of patients (\%).

c Median (min-max).

${ }^{\mathrm{d}}$ Geometric mean (min-max).

e Range.

$\mathrm{N}=$ number of patient.

recurrence the treatment administered was the same as that on admission, except in non-pregnant patients where the second recurrence was treated with chloroquine combined with primaquine $(0.25 \mathrm{mg} / \mathrm{kg}$ daily for 14 days $)$. The study in non-pregnant women was approved by the Ethics Committee of Mahidol University and the Karen Refugee Committee [8], and that in pregnant women [16] by the Ethics Committee of the Faculty of Tropical Medicine of Mahidol University and the Ethics Committee of the London School of Hygiene \& Tropical Medicine. Written informed consent was obtained from the patient for the publication of this report and any accompanying images.

\section{DNA extraction and microsatellite genotyping}

The blood samples from the non-pregnant patients were collected and stored on filter paper (Whatman $3 \mathrm{MM}$ ), while those from the pregnant women were whole blood with EDTA as anticoagulant stored at $-20^{\circ} \mathrm{C}$. Genomic DNA was extracted from a punched out $13 \mathrm{~mm}$ diameter spot for the filter paper samples (equivalent to about $35 \mu \mathrm{l}$ 
Table 2 Genetic diversity of $P$. vivax infections in pregnant and non-pregnant women based on 8 microsatellite markers

\begin{tabular}{|c|c|c|c|c|c|c|c|c|c|c|c|c|c|c|c|}
\hline \multirow[t]{2}{*}{ Episodes } & \multirow[t]{2}{*}{ Diversity } & \multirow[t]{2}{*}{ Patients } & \multirow[t]{2}{*}{$\mathrm{n}$} & \multicolumn{8}{|c|}{ Plasmodium vivax loci } & \multirow[t]{2}{*}{ Mean } & \multirow[t]{2}{*}{ SD } & \multirow[t]{2}{*}{ SE } & \multirow{2}{*}{$\begin{array}{c}p- \\
\text { value }\end{array}$} \\
\hline & & & & $\begin{array}{c}\mathrm{Pv} \\
1.501\end{array}$ & $\begin{array}{c}\mathrm{Pv} \\
3.27\end{array}$ & $\begin{array}{c}\mathrm{Pv} \\
3.502\end{array}$ & $\begin{array}{c}\mathrm{Pv} \\
6.34\end{array}$ & $\begin{array}{c}\mathrm{Pv} \\
8.504\end{array}$ & MS1 & MS5 & MS7 & & & & \\
\hline \multirow{6}{*}{$\begin{array}{l}\text { Admission } \\
\text { samples }\end{array}$} & \multirow{2}{*}{$\begin{array}{l}\text { No. of distinct alleles } \\
(A)\end{array}$} & $P$ & 18 & 9 & 9 & 7 & 7 & 6 & 5 & 6 & 6 & 6.88 & 1.46 & 0.52 & \multirow[t]{2}{*}{0.265} \\
\hline & & NP & 18 & 8 & 12 & 9 & 8 & 6 & 4 & 9 & 5 & 7.63 & 2.56 & 0.91 & \\
\hline & \multirow[t]{2}{*}{$H_{e}$} & $P$ & 18 & 0.919 & 0.895 & 0.889 & 0.739 & 0.856 & 0.772 & 0.838 & 0.742 & 0.831 & 0.07 & 0.03 & \multirow[t]{2}{*}{0.533} \\
\hline & & NP & 18 & 0.876 & 0.948 & 0.922 & 0.830 & 0.739 & 0.767 & 0.892 & 0.802 & 0.847 & 0.07 & 0.03 & \\
\hline & \multirow{2}{*}{$\begin{array}{l}\text { No. of distinct alleles } \\
\text { per locus }\end{array}$} & $P$ & 18 & 1.59 & 1.61 & 1.50 & 1.22 & 1.56 & 1.35 & 1.27 & 1.38 & 1.44 & 0.14 & 0.05 & \multirow[t]{2}{*}{$<0.001$} \\
\hline & & NP & 18 & 1.28 & 1.33 & 1.11 & 1.17 & 1.22 & 1.13 & 1.13 & 1.07 & 1.18 & 0.09 & 0.03 & \\
\hline \multirow{6}{*}{$\begin{array}{l}\text { Recurrent } \\
\text { samples }\end{array}$} & \multirow{2}{*}{$\begin{array}{l}\text { No. of distinct alleles } \\
\text { (A) }\end{array}$} & P & 44 & 9 & 11 & 10 & 12 & 8 & 6 & 9 & 9 & 9.25 & 1.83 & 0.65 & \multirow[t]{2}{*}{0.487} \\
\hline & & $N P$ & 36 & 13 & 14 & 10 & 11 & 8 & 6 & 8 & 8 & 9.63 & 2.76 & 0.98 & \\
\hline & \multirow[t]{2}{*}{$H_{e}$} & P & 44 & 0.882 & 0.824 & 0.872 & 0.901 & 0.846 & 0.736 & 0.848 & 0.839 & 0.844 & 0.05 & 0.02 & \multirow[t]{2}{*}{0.316} \\
\hline & & NP & 36 & 0.911 & 0.919 & 0.884 & 0.867 & 0.808 & 0.783 & 0.874 & 0.835 & 0.86 & 0.05 & 0.02 & \\
\hline & \multirow{2}{*}{$\begin{array}{c}\text { No. of distinct alleles } \\
\text { per locus }\end{array}$} & P & 44 & 1.49 & 1.40 & 1.30 & 1.50 & 1.36 & 1.26 & 1.27 & 1.51 & 1.38 & 1.11 & 0.04 & \multirow[t]{2}{*}{$<0.001$} \\
\hline & & $N P$ & 36 & 1.26 & 1.31 & 1.11 & 1.17 & 1.11 & 1.06 & 1.10 & 1.23 & 1.17 & 0.09 & 0.03 & \\
\hline \multirow{6}{*}{$\begin{array}{c}\text { All } \\
\text { samples }\end{array}$} & \multirow{2}{*}{$\begin{array}{l}\text { No of distinct alleles } \\
(A)\end{array}$} & P & 62 & 9 & 12 & 10 & 12 & 8 & 7 & 9 & 10 & 9.63 & 1.77 & 0.63 & \multirow[t]{2}{*}{0.320} \\
\hline & & $N P$ & 54 & 13 & 15 & 10 & 13 & 9 & 6 & 9 & 8 & 10.38 & 3.02 & 1.07 & \\
\hline & \multirow[t]{2}{*}{$H_{e}$} & P & 62 & 0.885 & 0.846 & 0.869 & 0.864 & 0.845 & 0.736 & 0.834 & 0.820 & 0.837 & 0.05 & 0.02 & \multirow[t]{2}{*}{0.340} \\
\hline & & NP & 54 & 0.906 & 0.921 & 0.888 & 0.848 & 0.781 & 0.770 & 0.866 & 0.836 & 0.852 & 0.06 & 0.02 & \\
\hline & \multirow{2}{*}{$\begin{array}{l}\text { No. of distinct alleles } \\
\text { per locus }\end{array}$} & P & 62 & 1.52 & 1.46 & 1.35 & 1.42 & 1.42 & 1.28 & 1.29 & 1.47 & 1.40 & 0.09 & 0.03 & \multirow[t]{2}{*}{$<0.001$} \\
\hline & & NP & 54 & 1.26 & 1.31 & 1.11 & 1.17 & 1.15 & 1.08 & 1.11 & 1.18 & 1.17 & 0.08 & 0.03 & \\
\hline
\end{tabular}

$\mathrm{P}=$ pregnant women and $\mathrm{NP}=$ non-pregnant women.

The No. of alleles and $H_{e}$ values were calculated from a data set in which only the predominant alleles at each locus was considered.

The No. of alleles per locus values were calculated from all detected alleles at each loci, divided by the total number of samples.

${ }^{a}$ Paired t-test was used to compare the means between groups.

of whole blood) and from $200 \mu$ l of the EDTA whole blood, using the QiAamp Blood kit (Hilden, Germany) eluted in a final volume of $100 \mu \mathrm{l}$ and stored at $-20^{\circ} \mathrm{C}$ until use. The presence of $P$. vivax was confirmed in all the samples by nested PCR [17]. Eight extensively polymorphic microsatellite markers: Pv1.501, Pv3.27, Pv3.502, Pv6.34, Pv 8.504 [10] and MS1, MS5 and MS7 [11], were used to genotype the isolates using published protocols. Two microliters of the purified genomic DNA were used as a template for amplification, and in cases where a secondary amplification was carried out, it was initiated with $1 \mu \mathrm{l}$ of the primary amplification product. The amplified fragments were analysed on an ABI 3130 Genetic Analyzer and by GeneMapper ${ }^{\circ}$ software version 4.0 (Applied Biosystems) to measure the variable length in the samples.

\section{Data analysis}

In any isolate the presence of one or more alleles at a particular locus was interpreted as a co-infection with two or more genetically distinct clones, i.e. multiple or polyclonal infections $[10,18]$. A locus was classed as having multiple alleles when the score of the minor peak was at least onethird the height of the predominant allele present for this locus. Samples from which the data was ambiguous were

Table 3 Multiple clone infections and multiplicity of infection in $P$. vivax

\begin{tabular}{|c|c|c|c|c|c|c|}
\hline \multirow[t]{2}{*}{ Episodes of infection } & Pregnant women & Non-pregnant women & \multirow{2}{*}{$\begin{array}{c}p- \\
\text { value }\end{array}$} & Pregnant women & Non-pregnant women & \multirow{2}{*}{$\begin{array}{c}p- \\
\text { value }\end{array}$} \\
\hline & \multicolumn{2}{|c|}{ Samples with multiple clones } & & \multicolumn{2}{|c|}{ MOI*, mean $( \pm S D)$} & \\
\hline \multirow[t]{2}{*}{ Admission } & $67 \%$ & $44 \%$ & 0.180 & 2.00 & 1.67 & 0.278 \\
\hline & (12/18 isolates) & (8/18 isolates) & & $( \pm 0.97)$ & $( \pm 0.84)$ & \\
\hline \multirow[t]{2}{*}{ Recurrence } & $55 \%$ & $53 \%$ & 0.875 & 2.05 & 1.64 & 0.110 \\
\hline & (24/44 isolates) & (19/36 isolates) & & $( \pm 1.41)$ & $( \pm 0.80)$ & \\
\hline \multirow[t]{2}{*}{ All episodes of infection } & $58 \%$ & $50 \%$ & 0.384 & 2.03 & 1.65 & 0.054 \\
\hline & (36/62 isolates) & (27/54 isolates) & & $( \pm 1.30)$ & $( \pm 0.81)$ & \\
\hline
\end{tabular}

${ }^{*} \mathrm{MOI}=$ multiplicity of infection. 


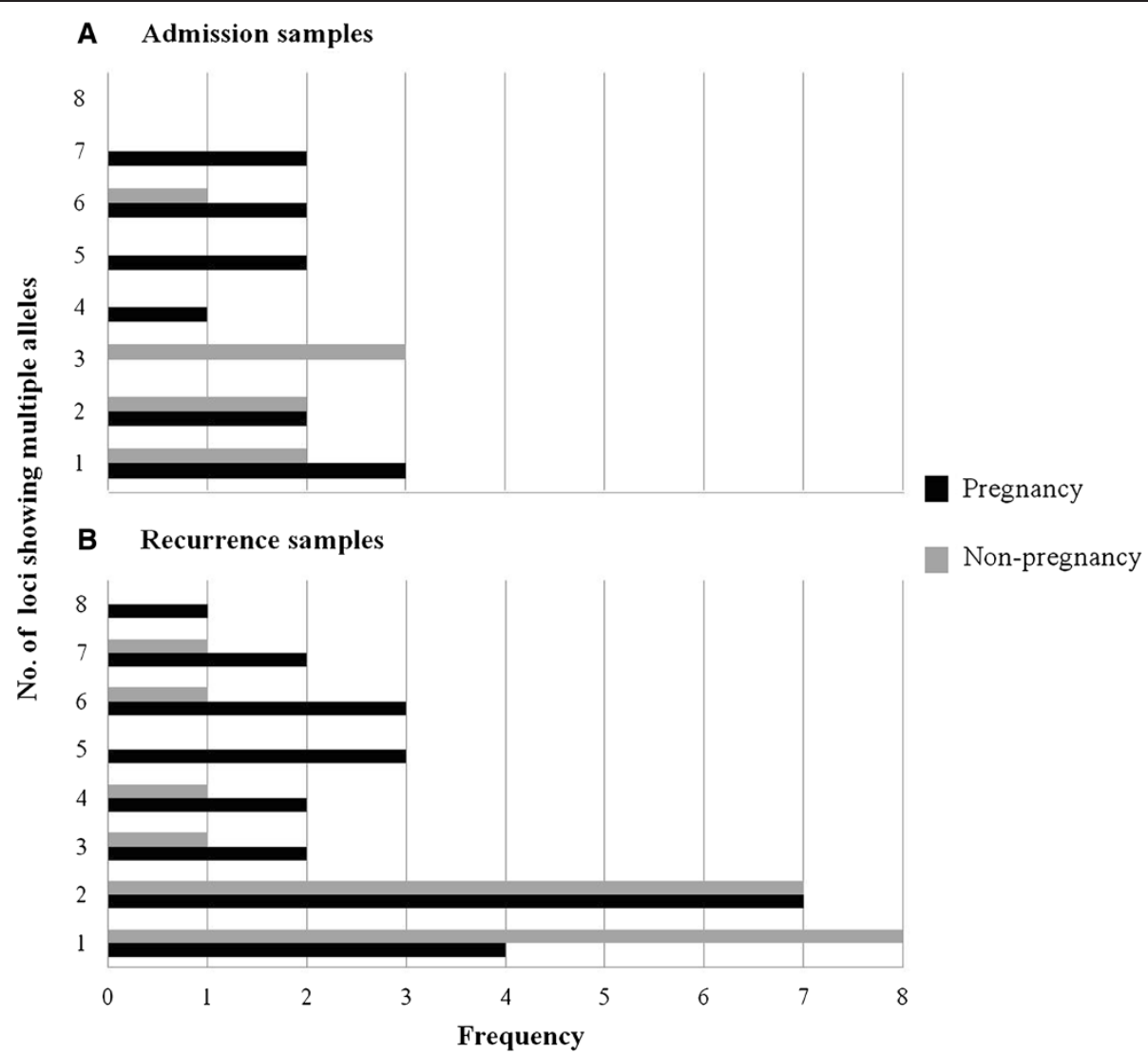

Figure 1 Frequency distribution of the number of loci with multiple alleles. The frequency of samples carrying multiple alleles for a given locus is plotted against the total number of loci in each sample found to be polyclonal.

re-amplified (maximum peak height $<300$ fluorescent units). The genetic diversity was measured using the predominated allele at each locus to calculate the expected heterozygosity $\left(H_{\mathrm{e}}\right)$. The formula defined as $H_{\mathrm{e}}=1 /(1-\mathrm{n})$ $\left(1-\sum p i^{2}\right)$ where $p$ is the frequency of $i^{\text {th }}$ allele. Expected heterozygosity $\left(H_{\mathrm{e}}\right)$ ranges between 0 and 1 , a value close to 1 indicated high genetic diversity levels in the population

Table 4 Linkage disequilibrium in $P$. vivax

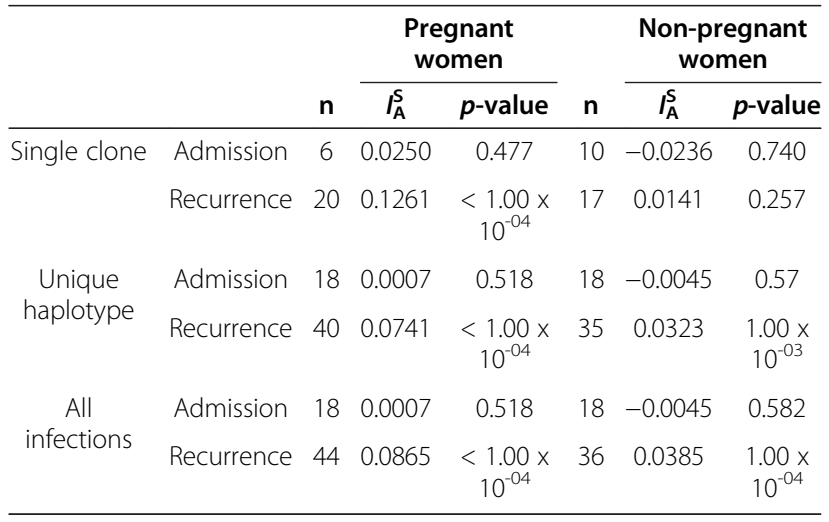

[19]. The multiplicity of infection (MOI) was also calculated as the maximum number of alleles observed at any locus. Multilocus linkage disequilibrium (LD) was calculated by using a standardized index of association $\left(I_{\mathrm{A}}^{\mathrm{S}}\right)$ $[20,21]$. This test compares the variance $(V D)$ of the number of alleles shared between all pairs of haplotypes observed in the population $(D)$ with the variance expected under random association of alleles $(V E)$ as follows: $I_{\mathrm{A}}^{\mathrm{S}}=$ $(V D / V E-1)(r-1)$, where $r$ is the number of loci analyzed [20]. $V E$ is derived from 10,000 simulated data sets in which alleles were randomly reshuffled among haplotypes. Significant linkage disequilibrium is detected if $V D$ is greater than $95 \%$ of the values derived from the reshuffled data sets. Data were analyzed with LIAN 3.1 [22]. Only the dominant alleles were considered to verify linkage. In order to detect possible bias due to equivocal assignment of haplotypes in multiple-clone infections, linkage disequilibrium (LD) was tested at three levels: (i) for all infections including those with more than one multi-allelic locus, (ii) for single clone infection, and (iii) for unique haplotypes only. In order to assess relatedness between isolates the genotype observed at 

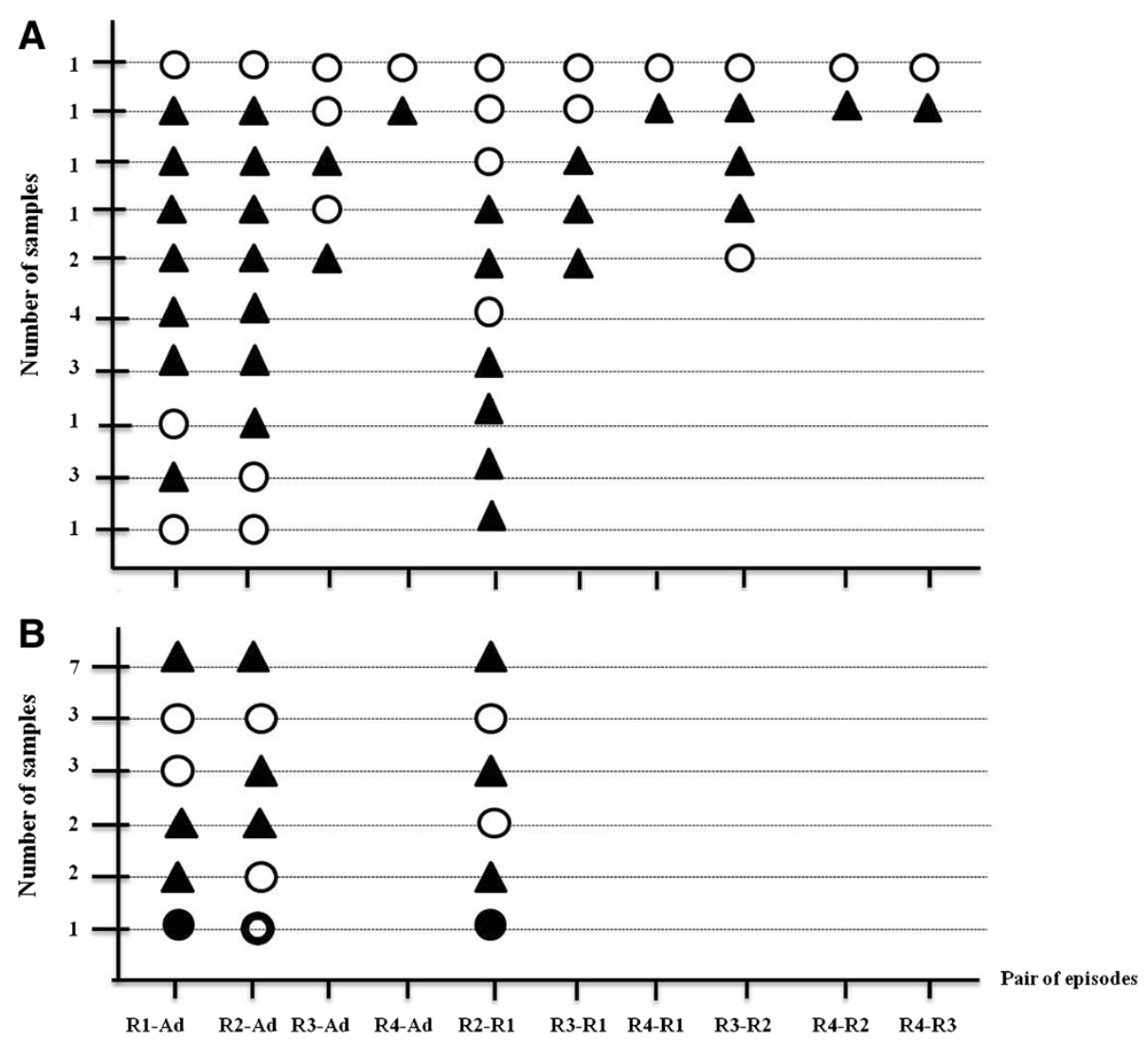

Figure 2 Genotypic relatedness of the $P$. vivax isolates obtained from individual pregnant $(A)$ and non-pregnant (B) patients. The number of samples displaying each pattern is provided in the $\mathrm{Y}$-axis. Pairwise comparisons were carried out for all possible combinations. The samples are coded as follows: $\mathrm{Ad}=$ admission, $\mathrm{R} 1=$ first recurrence, $\mathrm{R} 2=$ second recurrence, $\mathrm{R} 3=$ third recurrence, $\mathrm{R} 4=$ fourth recurrence. Two paired samples were classed as genetically different $(\boldsymbol{\Lambda})$ when the alleles variants differed by more than one repeat unit for at least one locus; the same if the alleles observed for all the loci are the same in the paired samples (o); and related if all or a subset of the allelic variants detected in one sample was also observed in the other paired sample. Given that two allelic variants from a given loci can differ by a single repeat unit because of artefactual slippage during amplification, related genotypes were classed as category " $\mathrm{A}$ " (o) if the allelic variants observed in a maximum of two loci differed by only by one repeat unit, and "B" $(\bullet)$ if three loci differed as above.

reappearances with that one admission day were compared: two genotypes were classed as related if a genotype was either a mixture of 2 adjacent microsatellite alleles at any one locus of which one was present in the paired sample, or if alleles at one or two loci differed only by one tandem repeat [13].

\section{Results and discussion}

A total of $116 P$. vivax isolates were selected for inclusion in this study: 54 were derived from 18 non-pregnant patients who all had two recurrent episodes, and 62 were obtained from 18 pregnant patients who all had two recurrences, four of whom then had a third and two more a fourth recurrence. The characteristics of the patients are provided in Table 1. Non-pregnant patients tended to be of lower age and to have a more frequent history of $P$. vivax infections in the year preceding the date of recruitment to the study than the pregnant patients. They also tended to have higher temperature and parasitaemia on admission. As expected, pregnant patients had a lower haematocrit than non-pregnant patients. The mean interval time to the first reappearance did not significantly differ between the two groups, 45 days for the pregnant $v \mathrm{~s}$ 43 days for the non-pregnant patients, nor did it differ for the second reappearance, 51 days $v s 48$ days. The second recurrence in non-pregnant women was treated with chloroquine and primaquine, and no further recurrences occurred. In the pregnant women the mean times to the third and fourth reappearances were 51 days and 32 days, respectively.

The microsatellite genotyping data were used to calculate the mean number of distinct alleles $(A)$, the heterozygosity $\left(H_{e}\right)$ and the mean number of distinct allelic variants for each locus in each sample (Table 2). The high number of distinguishable allelic forms observed for each locus and the high value of heterozygosity indicated that overall the $P$. 
Table 5 Comparison of the recurrent $P$. vivax genotypes

\begin{tabular}{|c|c|c|c|}
\hline & $\begin{array}{l}\text { Pregnant } \\
\text { women }\end{array}$ & $\begin{array}{l}\text { Non- } \\
\text { pregnant } \\
\text { women }\end{array}$ & $\begin{array}{c}p- \\
\text { value* }\end{array}$ \\
\hline & $\mathrm{N}=62$ & $\mathrm{~N}=54$ & \\
\hline $\begin{array}{l}\text { No. of recurrent Plasmodium vivax } \\
\text { infections }\end{array}$ & 44 & 36 & 0.617 \\
\hline $\begin{array}{l}\text { Median number of recurrences } \\
\text { (range) }\end{array}$ & $2(2-4)$ & $2(2)$ & 0.221 \\
\hline \multirow{2}{*}{$\begin{array}{l}\text { 1st recurrence and admission } \\
\text { episode similar }\end{array}$} & \multirow[t]{2}{*}{$3 / 18$} & $6 / 18$ & \multirow[t]{2}{*}{0.137} \\
\hline & & $1 / 18 B$ & \\
\hline \multirow{2}{*}{$\begin{array}{l}\text { 2nd recurrence and admission } \\
\text { episode similar }\end{array}$} & \multirow[t]{2}{*}{$5 / 18$} & $5 / 18$ & \multirow[t]{2}{*}{0.167} \\
\hline & & $1 / 18 \mathrm{~A}$ & \\
\hline $\begin{array}{l}\text { 3rd recurrence and admission } \\
\text { episode similar }\end{array}$ & $3 / 6$ & - & - \\
\hline $\begin{array}{l}\text { 4th recurrence and admission } \\
\text { episode similar }\end{array}$ & $1 / 2$ & - & - \\
\hline \multirow{2}{*}{$\begin{array}{l}\text { 2nd and 1st recurrence episodes } \\
\text { similar }\end{array}$} & \multirow[t]{2}{*}{$7 / 18$} & $5 / 18$ & \multirow[t]{2}{*}{0.729} \\
\hline & & $1 / 18 B$ & \\
\hline $\begin{array}{l}\text { 3rd and 1st recurrence episodes } \\
\text { similar }\end{array}$ & $2 / 6$ & - & - \\
\hline $\begin{array}{l}\text { 3rd and } 2 \text { nd recurrence episodes } \\
\text { similar }\end{array}$ & $3 / 6$ & - & - \\
\hline $\begin{array}{l}\text { 4th and 1st recurrence episodes } \\
\text { similar }\end{array}$ & $1 / 2$ & - & - \\
\hline $\begin{array}{l}\text { 4th and } 2 \text { nd recurrence episodes } \\
\text { similar }\end{array}$ & $1 / 2$ & - & - \\
\hline $\begin{array}{l}\text { 4th and 3rd recurrence episodes } \\
\text { similar }\end{array}$ & $1 / 2$ & - & - \\
\hline $\begin{array}{l}\text { Proportion of genotypically similar } \\
\text { recurrences }\end{array}$ & $27 / 80$ & $19 / 54$ & 0.864 \\
\hline \multirow{2}{*}{$\begin{array}{l}\text { In genotypically different recurrence } \\
\text { Median proportion of different } \\
\text { alleles (\%, rang) }\end{array}$} & $62.50 \%$ & $58.60 \%$ & \multirow[t]{2}{*}{0.562} \\
\hline & $\begin{array}{l}\text { (range } \\
12.5- \\
100 \%)\end{array}$ & $\begin{array}{l}\text { (range 12.5- } \\
100 \%)\end{array}$ & \\
\hline
\end{tabular}

Criteria for interpretation: $A=1$ or 2 markers (loci) different with $\leq 1$ possible stepwise mutation; $B=3$ markers (loci) different but $\leq 1$ repeat unit, different with $\leq 1$ possible stepwise mutation.

* Chi-square test used to compare in two patients groups.

vivax isolates circulating in the patients had a high degree of genetic diversity. The values did not significantly differ between parasites from pregnant and nonpregnant patients. There was a tendency that did not reach significance for samples from pregnant women to have a lower mean number of distinguishable alleles (A) than those from non-pregnant patients. On the other hand the number of distinct alleles per locus was significantly higher in pregnant $v s$ non-pregnant patients. This was reflected in the higher MOI observed in the combined admission and recurrence samples from the pregnant $v s$ non-pregnant women (Table 3), a difference that nearly reached significance. Nonetheless, the proportion of polyclonal infections was not statistically different between the samples obtained from either group (Table 3). When all the P. vivax samples from the admission $v s$ the recurrent samples were compared (Table 2), there was a significant difference in the mean number of distinct alleles (A) observed for the loci (7.25 vs 9.5, p-value 0.0001), and the isolates from the recurrent episodes showed a higher proportion of loci for which more than one allelic variant was noted in each sample (Figure 1). Linkage disequilibrium was assessed for clonal infections, infections with unique haplotype and all infections, in samples from pregnant patients and non-pregnant patients that were subdivided as admission and recurrence samples (Table 4). No evident for linkage disequilibrium was found for the parasites in the samples obtained on admission, or in the subgroup of recurrence samples with a monoclonal infection. However, significant linkage disequilibrium was found for the recurrent samples from the two groups when considered in their entirety or for the subgroup that has a unique haplotype (Table 4).

The genetic relatedness of the parasites obtained from each patient was assessed for all paired combinations (Figure 2, Table 5). Parasites from the first recurrent episode were different from those of the admission episode in 15 of the 18 pregnant patients and in 11 of the 18 non-pregnant patients, and a similar pattern was observed when the second recurrent episode parasites were compared to those of the first recurrence, in 11/18 and in $12 / 18$ of the pregnant and non-pregnant patients, respectively. In only $1 / 18$ and $3 / 18$ patients from the two groups were all the episodes of the same genotype.

It is clear from the analyses above that the P. vivax populations in this hypoendemic region on the Thai-Myanmar border exhibited high genetic diversity, with about half of the isolates harbouring polyclonal infections. The differences between the parasites present in admission and recurrent samples, or those in pregnant and non-pregnant patients were relatively subtle. The complexity of the populations (as assessed by the mean number of distinct alleles for the 8 microsatellite markers) was higher in the recurrent as compared to the admission isolates in both groups of patients. The episodes in pregnant women tended to contain parasites with a slightly higher mean number of distinct alleles per locus and consequently a higher MOI. However, there are three caveats connected with sampling that need to be considered before drawing firm conclusions. First, given the relatively small differences, a higher number of patients might be needed. Second, the isolates were collected a few years apart. The fact that the parameters of genetic diversity did not significantly differ between the two groups of samples, suggests that there was little change in the extent of the parasites' genetic diversity over the periods of sampling (1995-1999), though it is possible that the genetic diversity in the pregnant women does not reflect that in the general population. 
Third, the amount of blood equivalent to the DNA template aliquots used for genotyping was smaller for the non-pregnant $(0.7 \mu \mathrm{l})$ than for the pregnant $(4 \mu \mathrm{l}) \mathrm{pa}$ tients. This was inherent to the nature of the archived samples (dried blood spots and whole frozen blood, respectively). This six-fold difference in the volume of blood analyzed might account for the higher MOI in the pregnant women's episodes, though it should be mitigated by the fact that mean parasitaemia in pregnant patients was half that in non-pregnant women, and that a 33\% cut-off threshold was used to exclude the minor alleles. The main reason why this is unlikely is that it is inconsistent with the increase in allelic diversity in recurrent as compared to admission samples.

In conclusion, the parasites causing episodes in pregnant women had a higher genetic diversity than those in nonpregnant patients. This could be due to increased susceptibility to mosquito bites, reduced levels of immunity to infection, physiological changes in pregnancy especially if they affect reticulocyte dynamics, or a combination of these factors. In both patient groups the parasites at recurrence following treatment of the admission episode displayed a higher genetic complexity. In both pregnant and nonpregnant patients, the parasites at recurrence were genetically distinct from those on admission in about half the cases, as were the parasites from the first and the second recurrence. This pattern is similar to that observed earlier for relapsing $P$. vivax episodes in Thailand $[12,13]$. Differential accumulation of $P$. vivax in the placenta has not been noted in this area [6], though the phenomenon was observed in deliveries at Papua New Guinea [23], and in vitro cytoadhesion of $P$. vivax-infected red blood cells to ligands found in the placenta has been reported $[24,25]$. However, at the time when the samples analysed here were obtained, resistance of $P$. vivax to chloroquine, the treatment that was administered to both groups of patients, had not been recorded in Thailand $[8,26]$. Therefore, it is highly likely that the recurrent episodes analysed in this study were relapses originating from hypnozoites. The frequent heterologous nature of these relapse infections and their increased genetic diversity as compared to the admission infections are consistent with the activation of latent hypnozoites hypothesis [27].

\section{Competing interests}

The authors declare that they have no competing interests.

\section{Authors' contributions}

$\mathrm{RM}, \mathrm{FN}, \mathrm{MI}, \mathrm{GS}, \mathrm{ND}$ and NW were involved in the conception and design of the study. ST performed the laboratory experiments and the analysis. RM, FN and $\mathrm{CL}$ were involved in the samples collection. ST and MI wrote the first draft. GS and MI wrote the final draft of the manuscript. All authors read and approved the final manuscript.

\section{Acknowledgements}

We thank all pregnant women who provided a blood sample and all the staff at the Shoklo Malaria Research Unit who contributed to this study.
Thanks also to Dr. Leopoldo Villegas who provided the blood samples of pregnancies. This project was supported by the programme strategic scholarship for frontier research network for the joint Ph.D. Programme and the office of the higher education commission, the Wellcome Trust of Great Britain and Mahidol University and The Dean's Research Fund, Faculty of Tropical Medicine.

\section{Author details}

${ }^{1}$ Department of Clinical Tropical Medicine, Faculty of Tropical Medicine, Mahidol University, Bangkok, Thailand. '2Shoklo Malaria Research Unit, Mae Sot, Tak Province, Thailand. ${ }^{3}$ Mahidol Oxford Tropical Research Unit, Faculty of Tropical Medicine, Mahidol University, Bangkok, Thailand. ${ }^{4} C e n t r e$ for Vaccinology and Tropical Medicine, Churchill Hospital, Oxford, UK. ${ }^{5}$ Sanofi Pasteur, Lyon, France. ${ }^{6}$ INSERM UMR-S 945, F-75013, Paris, France. ${ }^{7}$ Université Paris 6, Pierre \& Marie Curie, Faculté de Médecine Pitié-Salpêtrière, Paris, France. ${ }^{8}$ Department of Molecular Tropical Medicine and Genetics, Faculty of Tropical Medicine, Mahidol University, Bangkok, Thailand.

Received: 3 April 2013 Accepted: 30 July 2013

Published: 6 August 2013

\section{References}

1. WHO: Malaria in pregnancy. Geneva: World Health Organization; 2007.

2. Steketee RW, Wirima JJ, Campbell CC: Developing effective strategies for malaria prevention programs for pregnant African women. Am J Trop Med Hyg 1996, 55(1 Suppl):95-100.

3. Luxemburger C, Ricci F, Nosten F, Raimond D, Bathet S, White NJ: The epidemiology of severe malaria in an area of low transmission in Thailand. Trans R Soc Trop Med Hyg 1997, 91:256-262.

4. Rijken MJ, Boel ME, Russell B, Imwong M, Leimanis ML, Phyo AP, Muehlenbachs A, Lindegardh N, McGready R, Renia L, Snounou G, Singhasivanon P, Nosten F: Chloroquine resistant vivax malaria in a pregnant woman on the western border of Thailand. Malar $J$ 2011, 10:113.

5. Nosten F, McGready R, Simpson JA, Thwai KL, Balkan S, Cho T, Hkirijaroen L, Looareesuwan S, White NJ: Effects of Plasmodium vivax malaria in pregnancy. Lancet 1999, 354:546-549.

6. McGready R, Davison BB, Stepniewska K, Cho T, Shee H, Brockman A, Udomsangpetch R, Looareesuwan S, White NJ, Meshnick SR, Nosten F: The effects of Plasmodium falciparum and $P$. vivax infections on placental histopathology in an area of low malaria transmission. Am J Trop Med Hyg 2004, 70:398-407.

7. Cogswell FB: The hypnozoite and relapse in primate malaria. Clin Microbiol Rev 1992, 5:26-35.

8. Luxemburger C, Van Vugt M, Jonathan S, McGready R, Looareesuwan S, White NJ, Nosten F: Treatment of vivax malaria on the western border of Thailand. Trans R Soc Trop Med Hyg 1999, 93:433-438.

9. Phyo AP, Lwin KM, Price RN, Ashley EA, Russell B, Sriprawat K, Lindegardh N, Singhasivanon P, White NJ, Nosten F: Dihydroartemisinin-piperaquine versus chloroquine in the treatment of Plasmodium vivax malaria in Thailand: a randomized controlled trial. Clin Infect Dis 2011, 53:977-984.

10. Imwong M, Nair S, Pukrittayakamee S, Sudimack D, Williams JT, Mayxay M, Newton PN, Kim JR, Nandy A, Osorio L, Carlton JM, White NJ, Day NP, Anderson TJ: Contrasting genetic structure in Plasmodium vivax populations from Asia and South America. Int J Parasitol 2007, 37:1013-1022.

11. Karunaweera NDFM, Hartl DL, Wirth DF: Fourteen polymorphic microsatellite DNA markers for the human malaria parasite Plasmodium vivax. Mol Ecol Notes 2007, 7:172-175.

12. Imwong M, Snounou G, Pukrittayakamee S, Tanomsing N, Kim JR, Nandy A, Guthmann JP, Nosten F, Carlton J, Looareesuwan S, Nair S, Sudimack D, Day NP, Anderson TJ, White NJ: Relapses of Plasmodium vivax infection usually result from activation of heterologous hypnozoites. J Infect Dis 2007, 195:927-933.

13. Imwong M, Boel ME, Pagornrat W, Pimanpanarak M, McGready R, Day NP, Nosten F, White NJ: The first Plasmodium vivax relapses of life are usually genetically homologous. J Infect Dis 2012, 205:680-683.

14. Arango EM, Samuel R, Agudelo OM, Carmona-Fonseca J, Maestre A, Yanow SK: Genotype comparison of Plasmodium vivax and Plasmodium falciparum clones from pregnant and non-pregnant populations in North-west Colombia. Malar J 2012, 11:392. 
15. Luxemburger C, Thwai KL, White NJ, Webster HK, Kyle DE, Maelankirri L, Chongsuphajaisiddhi T, Nosten F: The epidemiology of malaria in a Karen population on the western border of Thailand. Trans R Soc Trop Med Hyg 1996, 90:105-111.

16. Villegas L, McGready R, Htway M, Paw MK, Pimanpanarak M, Arunjerdja R, Viladpai-Nguen SJ, Greenwood B, White NJ, Nosten F: Chloroquine prophylaxis against vivax malaria in pregnancy: a randomized, doubleblind, placebo-controlled trial. Trop Med Int Health 2007, 12:209-218.

17. Snounou G, Viriyakosol S, Zhu XP, Jarra W, Pinheiro L, Do Rosario VE, Thaithong S, Brown KN: High sensitivity of detection of human malaria parasites by the use of nested polymerase chain reaction. Mol Biochem Parasitol 1993, 61:315-320.

18. Anderson TJ, Su XZ, Bockarie M, Lagog M, Day KP: Twelve microsatellite markers for characterization of Plasmodium falciparum from finger-prick blood samples. Parasitology 1999, 119:113-125.

19. Gunawardena S, Karunaweera ND, Ferreira MU, Phone-Kyaw M, Pollack RJ, Alifrangis M, Rajakaruna RS, Konradsen F, Amerasinghe PH, Schousboe ML, Galappaththy GN, Abeyasinghe RR, Hartl DL, Wirth DF: Geographic structure of Plasmodium vivax: microsatellite analysis of parasite populations from Sri Lanka, Myanmar, and Ethiopia. Am J Trop Med Hyg 2010, 82:235-242.

20. Hudson RR: Analytical results concerning linkage disequilibrium in models with genetic transformation and recombination. J Evol Biol 1994, 7:535-548.

21. Smith JM, Smith NH, O'Rourke M, Spratt BG: How clonal are bacteria? Proc Natl Acad Sci USA 1993, 90:4384-4388.

22. Haubold B, Hudson RR: LIAN 3.0: detecting linkage disequilibrium in multilocus data. Linkage Analysis. Bioinformatics 2000, 16:847-848.

23. Mayor A, Bardaji A, Felger I, King CL, Cistero P, Dobano C, Stanisic DI, Siba P, Wahlgren M, Del Portillo H, Mueller I, Menéndez C, Ordi J, Rogerson S: Placental infection with Plasmodium vivax: a histopathological and molecular study. J Infect Dis 2012, 206:1904-1910.

24. Carvalho BO, Lopes SC, Nogueira PA, Orlandi PP, Bargieri DY, Blanco YC, Mamoni R, Leite JA, Rodrigues MM, Soares IS, Oliveira TR, Wunderlich G, Lacerda MV, Del Portillo HA, Araújo MO, Russell B, Suwanarusk R, Snounou G, Rénia L, Costa FT: On the cytoadhesion of Plasmodium vivax-infected erythrocytes. J Infect Dis 2010, 202:638-647.

25. Chotivanich K, Udomsangpetch R, Suwanarusk R, Pukrittayakamee S, Wilairatana P, Beeson JG, Day NP, White NJ: Plasmodium vivax adherence to placental glycosaminoglycans. PLOS One 2012, 7:e34509.

26. Pukrittayakamee S, Chantra A, Simpson JA, Vanijanonta S, Clemens R, Looareesuwan S, White NJ: Therapeutic responses to different antimalarial drugs in vivax malaria. Antimicrob Agents Chemother 2000, 44:1680-1685.

27. White NJ: Determinants of relapse periodicity in Plasmodium vivax malaria. Malar J 2011, 10:297.

doi:10.1186/1475-2875-12-275

Cite this article as: Thanapongpichat et al: Microsatellite genotyping of Plasmodium vivax infections and their relapses in pregnant and nonpregnant patients on the Thai-Myanmar border. Malaria Journal 2013 12:275.

\section{Submit your next manuscript to BioMed Central and take full advantage of:}

- Convenient online submission

- Thorough peer review

- No space constraints or color figure charges

- Immediate publication on acceptance

- Inclusion in PubMed, CAS, Scopus and Google Scholar

- Research which is freely available for redistribution 